Brief Communication Arising from 'Evidence for human transmission of amyloid- $\beta$ pathology and cerebral amyloid angiopathy ${ }^{\prime 1}$

\title{
Seeds of Neuroendocrine Doubt
}

Claire Feeney, Gregory P Scott, James H Cole, Magdalena Sastre, Anthony P Goldstone, Robert Leech

Division of Brain Sciences, Imperial College London, Hammersmith Hospital Campus, London W12 0NN, UK

\section{Corresponding author}

Dr Claire Feeney, Computational, Cognitive and Clinical Neuroimaging Laboratory, 3rd Floor, Burlington Danes Building, Hammersmith Hospital, Du Cane Road, London, W12 0NN, UK. Email: c.feeney@imperial.ac.uk Telephone: +44 (0)7766 244299. Fax: +44 (0)207 5948921

\section{Sources of support}

Claire Feeney is funded by an MRC Clinical Research Training Fellowship

\section{Author Contributions Statement}

CF wrote the article. GS contributed to writing the article. JC, MS, AG and RL revised the manuscript and contributed to its content.

\section{Disclosure/Conflict of Interest}

There are no conflicts of interest 
Dear Editors,

The possibility of human-human transmission of Alzheimer's disease (AD) has never been considered until recently. A landmark study, published in September 2015 in Nature, reports the probable seeding of $\beta$-amyloid (a pathological hallmark of AD) from cadaveric human growth hormone (c-hGH) pituitary preparations who also developed iatrogenic Creutzfeldt-Jakob Disease (iCJD) from the same source ${ }^{1}$. Here, we argue that c-hGH was historically used to treat rare neuroendocrine disease and that these diseases or treatment with $\mathrm{GH}$ could result in $\beta$-amyloid pathology per se. Without a control group of the same patient cohort who neither received c-hGH nor developed iCJD, we believe that the authors are premature to infer an iatrogenic source of $A D$.

Cadaveric-hGH was previously used to growth hormone deficiency (GHD) in children. In the UK, GH was extracted from a cadaveric pool of approximately 400,000 pituitary glands and offered as an intramuscular treatment to selected patients. Given scarce resources and laborious extraction, its use was coordinated in the UK by a Medical Research Council working party in 1959 that was superseded by the Health Services Human Growth Hormone Committee in $1977^{2}$. In the UK, 1,908 people were registered as having received c-hGH from 1959 to 1985 when it was withdrawn worldwide after an initial report documenting three deaths from CJD in the US and one in the UK. This number rose to 226 incidences worldwide in $2012^{3}$. From 1985 onwards 
c-hGH became obsolete after being superseded by synthetic recombinant forms.

The diverse clinical indications for c-hGH treatment until 1985 are clearly presented in a comprehensive epidemiological review which utilised data from the Health Services Human Growth Hormone Committee records in the UK ${ }^{4}$. Of the 1908 patients registered as having received c-hGH in the UK, 1004 (52.6\%) had 'idiopathic' isolated GHD, 188 (10\%) 'idiopathic' panhypopituitarism, 230 (12.1\%) craniopharyngioma, 194 (10.2\%) other intracranial tumour, 62 (3.3\%) other neurological disease e.g. hydrocephalus, post meningitis and $62(3.3 \%)$ genetic short stature and growth delay or both and 44 (2.3\%) Turner's Syndrome. The remaining causes included PraderWilli syndrome, low birth weight, haematological disease, histiocytosis and septo-optic dysplasia. These well-recorded historical data demonstrate the heterogeneity and severity of neuroendocrine disease necessitating c-hGH treatment in the UK prior to 1985.

Supplementary material from the article in question reports the clinical details of all 8 patients and the indication for c-hGH treatment, summarized in Table 1. All patients received $\mathrm{c}-\mathrm{hGH}$ as children or adolescents and duration of treatment was for 2-12 years. From an etiological perspective, 3/8 subjects had panhypopituitarism (one also with mental retardation and microcephaly), $1 / 8$ craniopharyngioma and 4/8 are reported to have been treated for short stature alone. This is surprising as short stature alone was an uncommon indication for c-hGH prior to 1985 , although trials were starting to emerge for 
this indication just prior to the withdrawal of $\mathrm{c}-\mathrm{hGH}^{5}$. Short stature should not be confused with GHD as the former can be constitutional and the latter is a neuroendocrine disease which can lead to short stature. It is therefore likely that the 'short stature' group disguises a more complicated clinical picture.

At the other end of the clinical spectrum, one of the 4 patients reported as having moderate to severe gray matter and vascular $\beta$-amyloid pathology had a craniopharyngioma. These unusual pituitary tumours can be large, often require neurosurgery and/or cranial radiation and are prone to recurrence and multiple pituitary hormone deficiencies. Interestingly, the one patient in the sporadic CJD control group (aged 65 yrs. approx.) who also had similar levels of cerebral amyloid angiopathy (CAA) to the iCJD group was labelled as an outlier and it was commented that the subject had a surgical intervention 40 years before death (Jaunmuktane et al. Extended Data Figures 2\&3).

Jaunmuktane and colleagues' article was preceded by a case series from the same research group of the clinical, imaging, molecular and autopsy findings of the whole iCJD cohort $(n=22)^{6}$. One patient had a history of long term cognitive problems and additional MRI findings included one patient with septo-optic dysplasia and partial agenesis of the corpus callosum. It is not clear whether these particular patients were the ones included in the current article, but together with the historical records and the supplementary clinical details provided, highlight our argument that these patients had complex, rare and potentially severe neuroendocrine disease. 
With this in mind, an alternative hypothesis contributing to the findings is that these pre-existing and underlying conditions could by themselves lead to $\beta$ amyloid pathology and abnormal brain structure. $\mathrm{GH}$ is known to have various cognitive effects on the brain and isolated GHD in children can lead to lower $I Q$, impaired cognition, reduction brain volumes and white matter abnormalities $^{7,8}$. If GHD continued into adulthood (as it usually does) and was untreated then significant cognitive impairments are likely to have persisted ${ }^{9}$.

Traumatic brain injury (TBI) we now know is a common cause of GHD in children ${ }^{10}$ and this may not have been widely acknowledged prior to 1985 . TBI has been associated with widely distributed $A \beta$ deposition in post-mortem brain tissue ${ }^{11}$. Other neurological diseases including epilepsy, fragile $X$ syndrome, Down's syndrome and Parkinson's disease have all been linked with significant increased levels of amyloid precursor protein (APP) and $\beta$ amyloid protein questioning the specificity of this neuropathology to $A D$. A $\beta$ deposition may result from common underlying processes such as neuroinflammation, microglial activation and genetic factors ${ }^{12}$.

The authors comment on the striking CAA in this patient group and hypothesize that these individuals 'would be at increasing risk of cerebral haemorrhages had they lived longer'. However, large long-term follow up studies of children who received recombinant GH from 1985 onwards (i.e. no risk of human-human transmission) were found to have a 5-7 fold increased risk of cerebrovascular disease and, in particular, subarachnoid haemorhage, 
suggesting that this cohort have predisposing factors leading to increased risk of intracranial haemorrhage, irrespective of having received c-hGH ${ }^{13,14}$.

In conclusion, the authors present an interesting finding worthy of further investigation, but we feel that caution must be exercised in interpreting the result, especially in the absence of an appropriate control group. We believe it is also important to present a neuroendocrinological perspective and consider plausible alternative hypotheses to offer a balanced view on this high profile communication. 
Table 1

\begin{tabular}{|c|c|c|c|c|c|}
\hline Patient & Sex & History & $\begin{array}{l}\text { Substantial } \\
A \beta\end{array}$ & $\begin{array}{l}\text { Focal } \\
A \beta\end{array}$ & $\begin{array}{l}\mathrm{A} \beta \\
\text { angiopathy }\end{array}$ \\
\hline 1 & $M$ & $\begin{array}{l}\text { GH as a child for } \sim 5 \text { years for } \\
\text { panhypopituitarism }\end{array}$ & No & Yes & No \\
\hline 2 & $F$ & $\begin{array}{l}\text { GH as a child for } \sim 10 \text { years for } \\
\text { panhypopituitarism, mental retardation } \\
\text { and microcephaly }\end{array}$ & No & No & No \\
\hline 3 & $M$ & $\begin{array}{l}\text { GH as a child for } \sim 5 \text { years for short } \\
\text { stature }\end{array}$ & No & Yes & No \\
\hline 4 & $\mathrm{M}$ & $\begin{array}{l}\text { GH as a child for short stature from } \sim 7 \\
\text { for } \sim 12 \text { years }\end{array}$ & Yes & No & Yes \\
\hline 5 & $\mathrm{~F}$ & $\begin{array}{l}\text { Craniopharyngioma aged } \sim 10 \text { years, } \\
\text { GH from } 11 \text { years for } \sim 8 \text { years }\end{array}$ & Yes & No & No \\
\hline 6 & $M$ & $\begin{array}{l}\text { GH for short stature from } \sim 9 \text { years for } \\
\sim 5 \text { years }\end{array}$ & Yes & No & Yes \\
\hline 7 & $M$ & $\begin{array}{l}\text { GH as an adolescent for } \sim 3 \text { years for } \\
\text { panhypopituitarism }\end{array}$ & No & No & No \\
\hline 8 & $M$ & $\begin{array}{l}\text { GH for restricted growth } \\
\text { from } 16 \text { years for } \sim 2 \text { years }\end{array}$ & Yes & No & Yes \\
\hline
\end{tabular}

Summary table of the clinical indications for c-hGH treatment in childhood and incidence of $\beta$-amyloid for each patient (adapted from article text and supplementary information)

\section{References}

1 Jaunmuktane, Z. et al. Evidence for human transmission of amyloid-beta pathology and cerebral amyloid angiopathy. Nature 525, 247-250, doi:10.1038/nature15369 (2015).

2 Alatzoglou, K. S. \& Dattani, M. T. Genetic causes and treatment of isolated growth hormone deficiency-an update. Nature reviews. Endocrinology 6, 562-576, doi:10.1038/nrendo.2010.147 (2010).

3 Brown, P. et al. Iatrogenic Creutzfeldt-Jakob disease, final assessment. Emerging infectious diseases 18, 901-907, doi:10.3201/eid1806.120116 (2012).

4 Buchanan, C. R., Preece, M. A. \& Milner, R. D. Mortality, neoplasia, and Creutzfeldt-Jakob disease in patients treated with human pituitary growth hormone in the United Kingdom. BMJ : British Medical Journal 302, 824-828 (1991).

5 Buchanan, C. R., Law, C. M. \& Milner, R. D. Growth hormone in short, slowly growing children and those with Turner's syndrome. Archives of disease in childhood 62, 912-916 (1987). 
6 Rudge, P. et al. Iatrogenic CJD due to pituitary-derived growth hormone with genetically determined incubation times of up to 40 years. Brain : a journal of neurology 138, 3386-3399, doi:10.1093/brain/awv235 (2015).

7 Nyberg, F. \& Hallberg, M. Growth hormone and cognitive function. Nat Rev Endocrinol 9, 357-365, doi:10.1038/nrendo.2013.78 (2013).

8 Webb, E. A. et al. Effect of growth hormone deficiency on brain structure, motor function and cognition. Brain : a journal of neurology 135, 216-227, doi:10.1093/brain/awr305 (2012).

9 Falleti, M. G., Maruff, P., Burman, P. \& Harris, A. The effects of growth hormone $(\mathrm{GH})$ deficiency and $\mathrm{GH}$ replacement on cognitive performance in adults: a meta-analysis of the current literature.

Psychoneuroendocrinology 31, 681-691, doi:10.1016/j.psyneuen.2006.01.005 (2006).

10 Rose, S. R. \& Auble, B. A. Endocrine changes after pediatric traumatic brain injury. Pituitary 15, 267-275, doi:10.1007/s11102-011-0360-x (2012).

11 Graham, D. I., Gentleman, S. M., Lynch, A. \& Roberts, G. W. Distribution of beta-amyloid protein in the brain following severe head injury. Neuropathology and applied neurobiology 21, 27-34 (1995).

12 Westmark, C. J. What's hAPPening at synapses? The role of amyloid betaprotein precursor and beta-amyloid in neurological disorders. Molecular psychiatry 18, 425-434, doi:10.1038/mp.2012.122 (2013).

13 Carel, J. C. et al. Long-term mortality after recombinant growth hormone treatment for isolated growth hormone deficiency or childhood short stature: preliminary report of the French SAGhE study. The Journal of clinical endocrinology and metabolism 97, 416-425, doi:10.1210/jc.20111995 (2012).

14 Poidvin, A. et al. Growth hormone treatment for childhood short stature and risk of stroke in early adulthood. Neurology 83, 780-786, doi:10.1212/wnl.0000000000000737 (2014). 